\title{
FEED THE FUTURE IPM INNOVATION LAB: A CRITICAL ROLE IN GLOBAL FOOD SECURITY
}

\author{
R. Muniappan and Elvis A. Heinrichs, IPM Innovation Lab,Virginia Tech, 526 Prices Fork Road, Blacksburg, \\ VA 2406I, U.S.A describe USAID funded strategies to bring IPM to developing countries
}

Keywords: Integrated Pest Management, Food Security, IPM packages, papaya mealybug, bacterial wilt, South American tomato leafminer

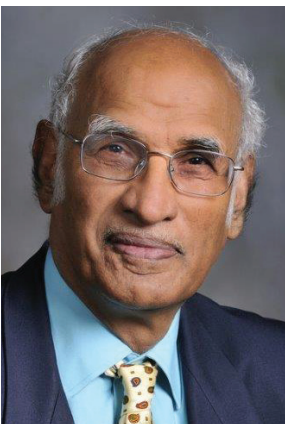

R. Muniappan

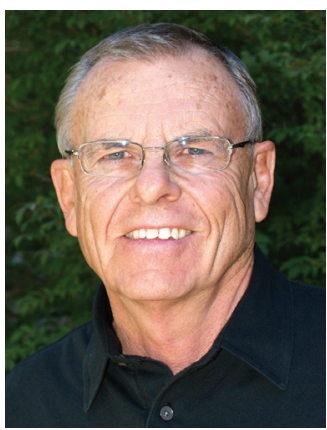

Elvis A. Heinrichs

\section{The need: food security}

The World Food Summit of 1966 defined "food security" as existing "when all people at all times have access to sufficient, safe, and nutritious food to maintain a healthy and active life." Food insecurity is part of a continuum that includes hunger (food deprivation), malnutrition (deficiencies, imbalances, or excess of nutrients) and famine. Although difficult to measure, food security statistics indicate that there is a food crisis in a stressed world. Consider these facts:

- 805 million people suffer from malnutrition.

- Most of the 805 million are in Southern Asia (35\%), subSaharan Africa (27\%), and Eastern Asia (19\%).

- $99 \%$ of the undernourished live in developing countries.

- 642 million people in Asia and the Pacific are undernourished.

- 6 million children's deaths/year are linked to malnutrition.

\section{The challenge}

The world faces three major challenges: 1) to match the rapidly changing demand for food, 2) to do so in ways that are environmentally and socially acceptable, and 3) to ensure that the world's poorest people are no longer hungry.

Crop yields have fallen in many areas due to declining investments in research, increasing water scarcity, land degradation, climate change, and biotic and abiotic stresses (insect pests, plant pathogens, nematodes, weeds, vertebrates, drought, flooding, extremes of temperature and nutrient deficiency). Globally, an average of $35 \%$ of crop yields are lost to pre-harvest pests and $10-20 \%$ to post-harvest pests. In the
2002-2003 period, pre-harvest losses were estimated to be $26-29 \%$ for soybean, wheat and cotton, and $31 \%, 37 \%$, and $40 \%$ for maize, rice, and potatoes respectively. Overall, weeds caused the highest potential losses $(32 \%)$, with animal pests and pathogens being less important (losses of $18 \%$ and $16 \%$ respectively). Invasive species, climate change, and the loss of biodiversity due to the misuse of pesticides amongst other factors all contribute to increased pest-induced losses.

World population is expected to reach nine billion in 2050 . To feed this population, there must be a $60-70 \%$ increase in food production. We must also figure out a way to deal with the effects of climate change. The area under cultivation is not expected to expand to meet the gap, and we have yet to meet it by increasing yield per unit area and reducing losses in field and post-harvest handling. A concerted effort to reduce these losses without jeopardizing environmental and public health concerns by adopting Integrated Pest Management (IPM) could reduce the loss by $50 \%$, leading to a needed increase in food production of only $30 \%$.

\section{Integrated Pest Management}

The IPM concept emerged out of the adverse impact of pesticides on non-target organisms and the development of pesticide resistance in targeted pests in the 1960s. The U.S. Environmental Protection Agency and USDA nurtured IPM by supporting major ventures like the Huffaker and Adkisson projects in the United States (Olsen et al., 2003). USAID also supported Consortium for International Crop Protection (CICP) activities in developing countries during this time.

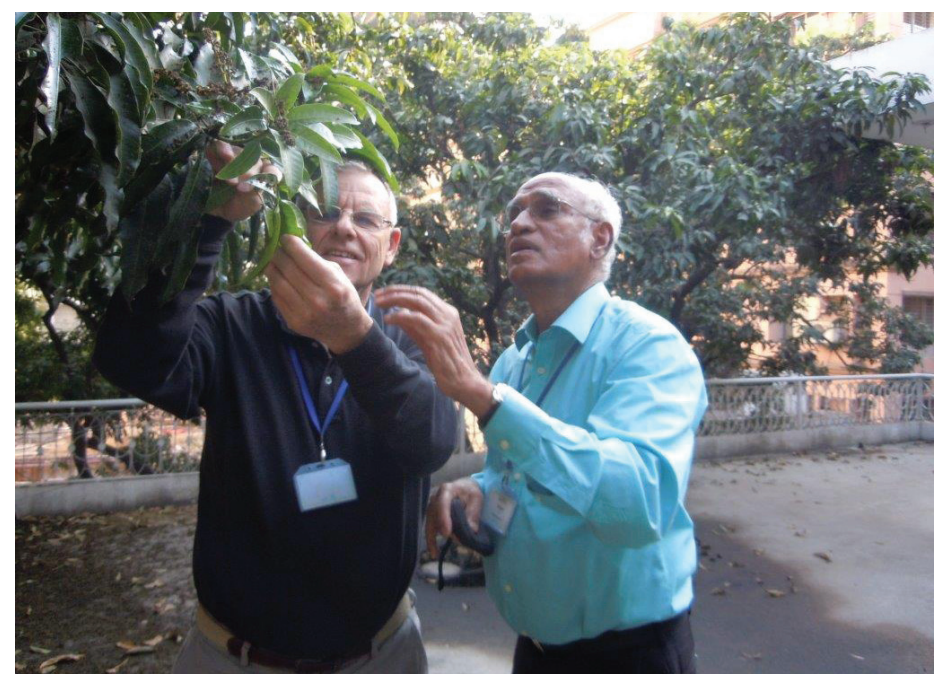

Figure I. Examining mango leaf hoppers in Bangladesh 


\section{The IPM CRSP}

In early 1990, USAID requested that the National Research Council (NRC) conduct a study on the need for IPM in developing countries (NRC, 1992). Endorsement of IPM by the NRC in 1992 resulted in the issuance of a Request for Application (RFA) for U.S. universities to form consortia and submit applications to manage the IPM Collaborative Research Program (CRSP). The consortium led by Virginia Tech was awarded the Cooperative Agreement to implement the program starting in October of 1993 for a duration of five years. Project goals were to reduce crop losses, increase farmer income, reduce pesticide use, reduce pesticide residues on export crops, improve IPM research and education program capabilities, improve pest monitoring, and increase the involvement of women in IPM decision-making and program design. The objectives were to identify and describe the technical, social, economic, political, and institutional factors affecting pest management, work with participating groups to design, test, and evaluate appropriate participatory IPM strategies, promote training and information exchange, and foster policy and institutional changes.

In the first five years, the participating countries were Jamaica, Guatemala, the Philippines, and Uganda. In 1998, USAID renewed the program for an additional fiveyear period, and the participating countries involved were expanded to nine: Albania, Bangladesh, Ecuador, Guatemala, Honduras, Jamaica, Mali, the Philippines, and Uganda.

During these two phases, the IPM CRSP in collaboration with its national partners concentrated on identifying the major pest and disease problems of high value vegetable crops, developing management tactics, and transferring technologies to farmers to replace the use of chemical pesticides. To cite a couple of examples, to overcome the soilborne bacterial wilt (Ralstonia solanacearum) of solanaceous crops, grafting on resistant rootstock, like wild eggplant, was adopted in Bangladesh. To manage the devastating tomato yellow leaf curl virus (TYLCV), the technology of a host-free period was introduced in Mali (Norton et al., 2005; Heinrichs et al., 2006).

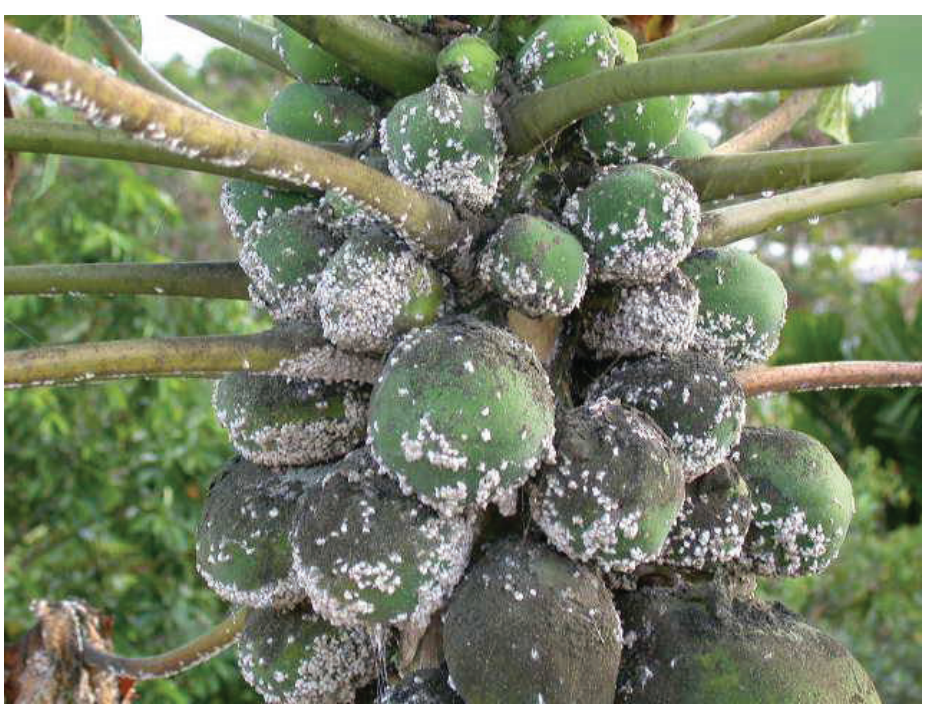

Figure 2. Papaya mealybug.
At the completion of the 10-year contract, USAID released a new RFA soliciting U.S. universities to submit proposals for the next five years of the IPM CRSP. Again the consortium headed by Virginia Tech won the award, and in this phase seven regions (Eastern Europe, West Africa, East Africa, Central Asia, South Asia, Southeast Asia and Latin America and the Caribbean (LAC)) encompassing over 20 countries were included. A concentrated effort was made to regionalize the program, as the pest problems were not bound by political boundaries, but presented themselves in ecological zones. During this phase, vegetable grafting technology was transferred in Asia from Bangladesh to the Philippines, Nepal, and India; in East Africa to Uganda and Kenya; in Latin America and the Caribbean to Ecuador and Honduras.

In 2008, once again, USAID arranged for a review of the IPM CRSP. Upon the positive findings of the review, a contract was extended until September 2014. During this phase, six regions and 17 countries were involved. It was decided that IPM CRSP would develop IPM packages for high-value vegetable crops and also place more emphasis on regionalization and globalization. The IPM package was defined as the development of non-chemical pesticide technologies for problems faced by farmers with a given crop from the time of preparation of the soil for planting to harvest. As an example, a package of practices for the management of tomato pests includes:

- Solarization of seed beds

- Selection of healthy and disease- and pest-free seeds of high-yielding varieties

- Use of plastic seedling trays and coconut dust/pith as a seedling medium

- Treating seeds and/or seedlings with Trichoderma spp., Pseudomonas fluorescens and Bacillus subtilus

- Roguing diseased seedlings in the nursery to prevent introduction in the field

- Application of neem cake for control of nematodes

- Grafting seedling scions of desired varieties on rootstock of resistant varieties

- Staking and mulching

- Setting up sticky colored traps

- Planting marigolds to reduce the nematode population in the field

- Use of pheromone traps for monitoring Helicoverpa armigera, Spodoptera litura, and Tuta absoluta

- Use of biopesticides such as Beauveria bassiana, Metarhizium anisopliae, Bacillus thuringiensis, Paecilomyces sp., and nucleopolyhedrosis viruses

- Use of botanical pesticides, e.g. neem

- Release of biocontrol agents like Trichogramma sp., Hebrobracon hebetor and others

- Adoption of a host-free period for management of Tomato yellow leaf curl virus disease

- Adoption of conservation biological control by reducing the use of chemical pesticides that adversely affect beneficial organisms

Similar packages have been developed for other tropical vegetables and disseminated in host countries through research and extension arms. In addition, several national, regional, and international workshops have been conducted in specialized 


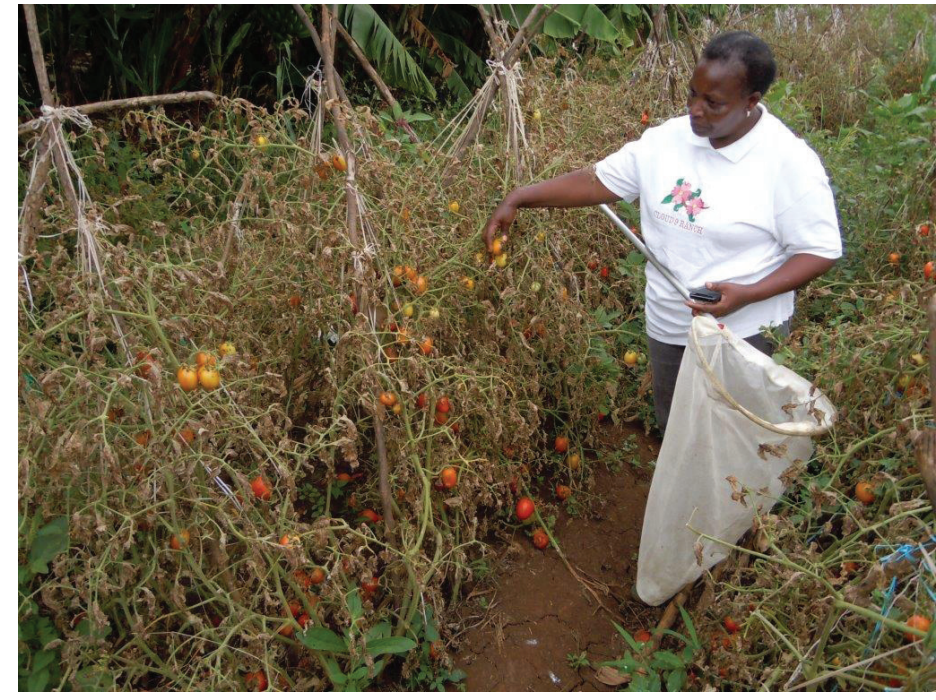

Figure 3. Tuta absoluta damaged tomato field in Kenya.

areas, such as 1) the production and use of Trichoderma spp., Pseudomonas fluorescens, and Beauveria bassiana; 2) virus diseases of vegetable crops; 3) papaya mealybug (Paracoccus marginatus) control; 4) grafting vegetable seedlings; 5) seed-borne diseases of vegetables; and 6) management of Tuta absoluta.

A unique approach taken in this phase of the program was to work closely with the USAID value chain projects by training their technicians in the concepts of IPM so that they could take these technologies to farmers. In this process, we found that the technologies did indeed reach the farmers. However, we came to know that the recommended products such as Trichoderma and pheromones were not available in the villages. To remedy this situation, we worked with a local entrepreneur in the production of biopesticides and trained agro-dealers for their distribution. This approach has greatly increased the adoption rate of IPM technologies in some selected countries, and we are in the process of introducing this approach to other countries.

IPM CRSP technologies have had significant impacts on food security. One of the most significant activities carried out was the biological control of papaya mealybug in India. The IPM CRSP was the first to identify the exotic invasive papaya mealybug in India in August 2008. In collaboration with Indian institutions, the USAID mission in India, and USDA APHIS, parasitoids of this mealybug from a Puerto Rico laboratory were introduced to India in August 2010, resulting in complete suppression of the mealybug by February 2011. This biological control effort has resulted in a benefit of $\$ 500$ million to $\$ 1.34$ billion to India (Myrick et al., 2014). A partial analysis of the impact of IPM technologies introduced to various countries has resulted in a benefit of over $\$ 2$ billion, and we estimate that a complete analysis of all the technologies introduced will result in more than double that amount.

In 2012, the introduction of the South American tomato leaf miner, Tuta absoluta, into Senegal resulted in the involvement of the IPM Innovation lab (USAID changed the name CRSP to Innovation Lab in 2013) in tracking this pest and advising various countries in Africa and Asia about the

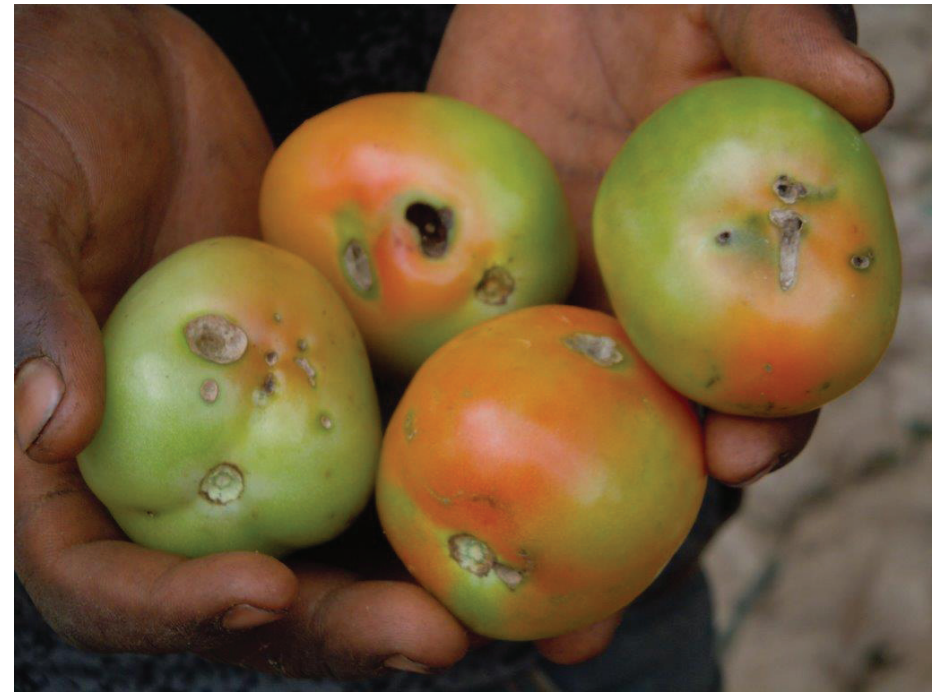

Figure 4. Tuta absoluta damaged tomato fruits.

seriousness of its invasion and appropriate management strategies. To sensitize agricultural administrators, scientists, and regulatory officials in West, Central, and East Africa, two workshops were conducted in May and November 2013 in Dakar, Senegal and Addis Ababa, Ethiopia, respectively. Since the invasion of this pest into India, advance forewarning workshops were conducted in Nepal and Bangladesh in February and June 2015, respectively. The organization of additional workshops in invaded countries, as well as in regional and international fora, are being contemplated.

Our efforts in the globalization of vegetable IPM components such as the use of coconut dust/pith as a seedling medium, the treatment of seeds and/or seedlings with Trichoderma spp. and Pseudomonas fluorescens, grafting to overcome soil-borne diseases, staking, mulching, trellising, the use of pheromone traps, and biopesticides have gained momentum, and current adoption rates vary from country to country, but are steadily expanding.

\section{Feed the future IPM innovation lab}

In 2014, USAID released another RFA requesting proposals from U.S. universities to continue IPM Innovation lab activities in Feed the Future countries. Virginia Tech was again successful in securing the award and has continued developing and implementing IPM for vegetables, fruit, and grain crops in seven countries in Asia and Africa for an additional five years. The current projects are:

- Rice IPM: Cambodia

- Export fruits IPM: Vietnam

- Vegetable and mango IPM: Bangladesh, Cambodia and Nepal

- Climate change and biodiversity: Nepal

- Vegetable IPM: Ethiopia, Kenya and Tanzania

- Grains IPM: Ethiopia, Kenya and Tanzania

- Modeling of distribution and spread of the South American tomato leafminer, Tuta absoluta, and the groundnut leafminer, Aproaerema modicella: Asia and Africa

- Invasive species Parthenium in Africa 
In closing, it is evident that the IPM Innovation Lab is playing a vital role in the struggle for global food security. This will continue through the new Feed the Future IPM Innovation Lab which has expanded beyond a limited number of vegetables to include more vegetables, rice, fruit, maize, chickpea, climate change and invasive species. Considering the role of the IPM Innovation Lab in promoting global food security, the following quote of the Father of the Green Revolution, Norman Borlaug, is appropriate:

"The only way that the world can keep up with food production to the levels that are needed with a growing world population is by the improvement of science and technology, and with the right policies that permit the application of that science and technology."

\section{Acknowledgement}

Support for the programs reported in the article by the USAID projects: LAG-G-00-93-00053, EEP-A-00-04-00016-00, andAID-OAA-L-15-00001 is acknowledged.

\section{References}

Heinrichs, E.A., Kenny, R., Muniappan, R., Rich, M. \& Vaughan, L. 2006. Integrated Pest Management Collaborative Research Support Program Phases I and II - Final Report. Office of International Research, Education and Development, Virginia Tech, Blacksburg, VA, USA 194 p.

Myrick, S., Norton, G.W., Selvaraj, K.N., Natarajan, K. \& Muniappan, R. 2014. Economic impact of classical biological control of papaya mealybug in India. Crop Protection 56, 82-86.

Norton, G.W., Heinrichs, E.A., Luther, G.C. \& Irwin, M.E. 2005. Globalizing Integrated Pest Management. A Participatory Research Process. Blackwell Publishing, Ames, Iowa, USA 338 p.

NRC. 1992. Toward Sustainability. An Addendum on Integrated Pest Management as a Component of Sustainability Research. Board on Agriculture, Board on Science and Technology for International Development, National Academy Press, Washington, D.C., USA 35 p.
Olsen, L., Zalom, F. \& Adkisson, P. 2003. Integrated Pest Management in the USA. In, K.M. Maredia, D. Dakouo, \&D. Mota-Sanchez (eds.). Integrated Pest Management in the Global Arena. CABI Publishing, Oxon, UK pp 249-271.

Muniappan is an entomologist who has specialized in biological control and integrated pest management research in the tropics for more than 45 years. He is the director for the IPM Innovation Lab, an international program funded by USAID and managed by Virginia Tech. His work experience spans through Asia, Africa, Pacific, Caribbean and Latin America. His work on the papaya mealybug in India alone brought about economic benefits of well over $\$ 500$ million, saving the livelihood of thousands of farmers. He has served in management positions for international scientific bodies. As an honorary member of the International Organization for Biological Control (IOBC), he was instrumental in establishing the IOBC global working groups on Chromolaena in 1988 and on Parthenium in 2009. He is a recipient of the Board for International Food and Agricultural Development of the United States Agency for International Development award for Scientific Excellence in 2014.

Dr. E. A. "Short" Heinrichs is an entomologist with expertise in integrated pest management (IPM). His research focus has been on the integration of resistant crop varieties with other control tactics in pest management systems. Crop emphasis has been tropical rice. He has worked in many countries with longterm experience in agricultural development programs in Asia, South America and Africa. IPM experience involves cooperation with international agencies including USAID, World Bank, African Development Bank and international agricultural centers (IARCs) of the CGIAR. Dr. Heinrich's research has been published extensively. He has expertise in the development of IPM training programs for extending agricultural technology to extension workers and farmers. Administrative experience includes Head of IRRI's Department of Entomology in the Philippines, Head of the Department of Entomology at Louisiana Sate University and Program Leader at WARDA in Côte d'lvoire. He has served as a Professor on the faculties of three universities in the USA and the Philippines. Dr. Heinrich's current activities include (I) Asia Program Manager, IPM Innovation Lab, VA Tech, (2) Emeritus Assistant Director, University of Nebraska (3) Research Professor, UNL Dept. of Entomology; and (4) Secretary General, International Association for the Plant Protection Sciences (IAPPS).

\section{Similar articles that appeared in Outlooks on Pest Management include - 2009 20(5) 197;} 2012 23(I) 13;2013 24(5) 225; 2015 26(I) 4 
Reproduced with permission of the copyright owner. Further reproduction prohibited without permission. 